\title{
Editorial \\ Delivering Caring Amidst The Pandemic: Reflection on The Conduct of Community
}

Indonesian Nursing Journal of Education and Clinic (INJEC)

Volume 5, Issue 2, December 2020

injec.aipni-ainec.org/index.php/INJEC/index

The Association of Indonesian Nurse

Education Center (AINEC)

https://injec.aipni-

ainec.org/index.php/INJEC/issue/view/I6/show Toc

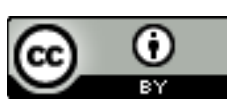

\author{
Joel Rey Acob, DNS, RN \\ Dean, College of Nursing, Visayas State University, Philippines \\ email:mjoel.acob@vsu.edu.ph
}

Since the inception of Covid-19, transactions have altered, including delivery of care. Those having access in addressing their health-related needs are fortunate, but for the greater number of the population their chance to acquire a better life has fallen. Healthcare demands have doubled while its workers have retrenched. Nurses and frontliners have experienced burnout with many narratives of struggles. These may not only substantial in the Philippines, but likely also apply to neighboring countries sharing parallel ideas and culture.

The pandemic has meant transitioning to a newer conventional communicates with symbolic opportunities. For healthcare industries, neither pandemic nor any form of disaster hinders the continuance of care. Nursing as a caring character should continue, remain and proceed amidst any circumstance. Similarly, executing programs toward betterment of health at the primary level should be conveyed uninterrupted.

Community health concerns the care appraisal, which reveals features of the biological societies. It is aimed at strengthening betterment to and among people. In meeting the needs of the clientele, health workers properly identify specific problems. These dilemmas are enriching ingredients to plan management schemes in the wellbeing of community partners. Community health focuses on promotion and prevention activities. The therapeutic use of self-, appropriate utilization of skills and rightful application of fundamental understanding generally constructs primary care. Although indigenous reasoning is claimed effective, healthy villagers are enabled competently through designing tailored-fit and culturallysensitive programs. Adaptation to changing health systems suits susceptibility when recipients are regarded as co-creators in the developmental revolution toward improved and protected wellbeing.

Contrasting to the idea of nurturing healthy population across lifespan, primary health systems may encounter challenges. Conceptual blueprints reveal understandings which lead to strategic mapping of interventions. The lack of support, untrained volunteer health workers, poor integration of Kadres to existing health structures, compensation, and policy concerning primary health are obstacles of health advancement.

To this end, health care institutions are called to recognize to do the best of their capacities. Saving lives in the period of pandemic is not unusual, since nursing's business is caring. The Visayas State UniversityCollege of Nursing heart-to-head indicates ensuring healthy populations. Conduct of community projects for health and wellbeing (SDG 3) proceeds amidst Covid-19.

On a reflective note, guaranteeing healthy community needs requires community participation. Recipients of care are seen as part of the planning process. Their participation should be from South-to-South to secure sustenance. Finally, mentoring people as part of the core indicates ethical management and a moral obligation. Training, education and continuing education are confirming attitudes in these trying times. 